\title{
The Use of Spreadsheets and Service-Learning Projects in Mathematics Courses
}

\author{
Morteza Shafii-Mousavi \\ Indiana University South Bend \\ P.O. Box 7111 \\ South Bend, IN 46634 \\ 574-520-4516 \\ mshafii@iusb.edu
}

\author{
Paul Kochanowski \\ Indiana University South Bend \\ P.O. Box 7111 \\ South Bend, IN 46634 \\ 574-520-4516 \\ pkochano@iusb.edu
}

\begin{abstract}
In the Indiana University system, as well as many other schools, finite mathematics is a prerequisite for most majors, especially business, public administration, social sciences, and some life science areas. Statisticians Moore, Peck, and Rossman [23] articulate a set of goals for mathematics prerequisites: including instilling an appreciation of the power of technology and developing skills necessary to use appropriate technology to solve problems, developing understanding, and exploring concepts. This paper describes the use of Excel spreadsheets in the teaching and learning of finite mathematics concepts in the linked courses Mathematics in Action: Social and Industrial Problems and Introduction to Computing taught for business, liberal arts, science, nursing, education, and public administration students. The goal of the linked courses is to encourage an appreciation of mathematics and promote writing as students see an immediate use for quantitative and communication skills in completing actual service-learning projects. The courses emphasize learning and writing about mathematics and the practice of computer technology applications through completion of actual industrial group projects. ${ }^{1}$ Through demonstration of mathematical concepts using Excel spreadsheets, we stress synergies between mathematics, technology, and real-world applications. These synergies emphasize the learning goals such as quantitative skill development, analytical and critical thinking, information technology and technological issues, innovative and creative reasoning, and writing across the curriculum.
\end{abstract}

\section{Keywords}

Excel spreadsheet demonstrations, service-learning Projects, linked mathematics and technology courses

\footnotetext{
${ }^{1} \mathrm{~A}$ detailed discussion of various aspects of these courses is found in $[13],[14],[15],[16],[17],[34],[35],[36]$
}

Permission to make digital or hard copies of all or part of this work for personal or classroom use is granted without fee provided that copies are not made or distributed for profit or commercial advantage and that copies bear this notice and the full citation on the first page. To copy otherwise, or republish, to post on servers or to redistribute to lists, requires prior specific permission and/or a fee. Copyright (C) JOCSE, a supported publication of the Shodor Education Foundation Inc.

\section{INTRODUCTION}

Business and economics students generally are required to take introductory mathematics courses, traditional finite mathematics and calculus, as prerequisites for statistics, operations research, finance, and other quantitative business and economics offerings. Such prerequisites often are offered in the mathematics department and taught with little regard to how students will use the concepts and techniques in their majors. O'Shea and Pollatesek [25], for example, argue that the traditional curricular structures from elementary through junior year college mathematics courses (algebra, geometry, pre-calculus, and calculus) do not allow students to encounter the range of ideas embraced by modern mathematics. Students seldom see these ideas used and rarely have sufficient time for real mastery. Statisticians Moore, Peck, and Rossman [23] believe the highest priority requirements of statistics from the mathematics curriculum to be that students develop skills and habits of mind for problem solving and for generalization.

Along these lines Moore, Peck, and Rossman [23]articulate a set of goals for mathematics prerequisites:

1. Emphasize multiple presentations of mathematical objects.

2. Provide multiple approaches to problem solving, including graphical, numerical, analytical, and verbal.

3. Adopt learning-centered instruction and address students' different learning styles by employing multiple pedagogies.

4. Insist that students communicate in writing and learn to read algebra for meaning.

5. Use real, engaging applications through which students can learn to draw connections between the language of mathematics and the context of the application.

6. Instill appreciation of the power of technology and develop skills necessary to use appropriate technology to solve problems, develop understanding, and explore concepts.

7. Align assessment strategies with instructional goals.

Moore, Peck, and Rossman (hereafter MPR) [23] note that statisticians are less concerned with specific content coverage but more with the development of the skills and habits of 
mind to solve problems, generalize ideas, and model servicelearning problems. In short, satisfying these goals necessitates designing a freshman-level math course that exposes students to a variety of mathematical ideas and technological applications that prepare students to deal with statistical topics, data, and modeling.

\section{INNOVATIVELY LINKED MATHEMAT- ICS AND TECHNOLOGY COURSES}

Mathematics in Action: Social and Industrial Problem is a project-based mathematics course, [15] and [36], which overcomes the tension between the goals set out by statisticians, the content concerns of mathematics instructors, and weaknesses of using traditional approaches. The course is part of a National Science Foundation sponsored grant Mathematics and Science Throughout the Undergraduate Curriculum awarded to Indiana University. The NSF grant overcomes cultural impediments to reform, such as reluctance by many teachers to change from traditional lecture type teaching formats. The grant rewards risk taking interdisciplinary approaches, requires reform approaches, and encourages enrolling students who have failed traditional approaches. Mathematics in Action teaches [16] freshmen in Business, Economics, Education, Liberal Arts and Sciences, Nursing, and School of Public and Environmental Affairs. Mathematics in Action uses an interdisciplinary environment in which a diverse group of students and faculty apply learning-centered approaches and engage in discussions. The approach taken in the course resolves the lecturing centered weakness of the traditional approaches. In the course, students learn mathematics by a mixture of traditional instruction and modeling applications. These skills allow students to solve actual service-learning projects for business, industry, social and governmental agencies. By using servicelearning projects, Mathematics in Action overcomes the relevance weakness of the traditional freshman level finite mathematics course (MPR goal 5). Organizations, which supply such projects, universally instill in students a sense of the projects' worth. For example, the American Diabetes Association informed students that their efforts would help the organization estimate geographical locations of those in dire need of critical health care services such as testing for diabetes. The relevance issue and lack of statistical content are largely overcome as students involve themselves (MPR goals $1 \& 2$ ) in narrowing the problem, struggling to find the relevant data, and attempting to discover, learn, and apply those tools that will lead towards a solution. Conceptual understanding of the traditional core mathematical topics takes place (to satisfy the prerequisite concerns) by

1. Teaching core topics required by replaced traditional courses and

2. Using the tools to solve hands-on service-learning projects and individual projects designed to apply technology [35].

Students use actual data and statistical tools in solving actual business and social problems (Goals 1, 3, 4, \& 5 and modeling concerns mentioned by MPR). Thus, the artificiality issue of the applications is resolved. Moreover, students analyze surveys and collect data in a large real engaging environment. Their learning environment extends beyond the classroom to the library, service-learning organization, laboratory, and community. They think statistically and practice statistical reasoning. They use elements such as probabilities, estimations, percents, and computer technology routinely. Students develop skills, in mathematics, statistics, teamwork, data gathering, and communications (oral and written). (MPR goals $3 \& 4$ ). Students see the needs for applying technological tools such as Microsoft Excel Spreadsheets to manipulate the data, solve the problem, and present the result (MPR goal 6). This instills an appreciation of the power of technology. They use appropriate technology to solve problems that are unsolvable by more primitive methods.

The use of real data for the projects and the ability to find a solution has highlighted to us the necessity to use computer technology and modern software. We had not envisioned this need the first time we taught the Mathematics in Action course. Initially, we thought that students could use graphing calculators to analyze the data sets for their projects. This was very naive on our part. Many servicelearning projects involve large data sets or large numbers of calculations that simply cannot be done on a hand held calculator due to insufficient memory. A delinquency loan rate project for a large financial institution, for example, had approximately 140,000 loan accounts for each of twelve months (longer periods were also available). A routing problem using the traveling salesperson algorithm was too large even for the computer. It had to be broken into parts, and then reconstructed to obtain solutions. This unexpected need for technology turned out to be a blessing in disguise (though this is not necessarily the way we thought about it that first year). The need to use modern day technology has led to an awareness and appreciation by our students of the power of merging technology and mathematics to solving servicelearning problems. This has become one of the more important learning outcomes from the use of service-learning projects.

For five years, Mathematics in Action was taught with instruction on technology done through class projects and out of class tutorials. Students complained about the out of class time demands placed on them for a three-credit hour course. This approach also placed a tremendous burden on the faculty teaching Mathematics in Action. Instructors in the course had to not only teach the course, work with five or six organization on projects, coach student teams on the mathematics required for the projects, but on top of all of these, teach students how to use applications software such as Excel, Access, SPSS, Microsoft Word, etc. Prior to coming into this freshman mathematics course virtually none of the students had experience with computer applications. Nonetheless, all students on the IUSB campus are required to take at least one technology course. ${ }^{2}$

Linking Mathematics in Action and computer technology solved two major problems: 1) the linkage reduced student frustration over course time demand. Students would now receive credit for two required courses, making time demands placed on students commensurate with the credits received; and 2) the linkage further lessened the burden placed on

\footnotetext{
${ }^{2}$ For a detailed discussion of linking introductory mathematics and technology courses see [34]. Projects differ in the tools needed for solutions. For example, with very large data bases Access was first use to link various parts of those data bases so that they could be then used in Excel.
} 
faculty. Each faculty member is given credit for one of the linked courses. ${ }^{3}$ This linkage also resulted in several benefits:

1. Mathematical projects were used to illustrate and practice various computer applications;

2. Computer applications skills were used to solve various mathematical problems;

3. The ability to use computer technology to solve large scale problems enhanced the appreciation by students of the power of applied mathematics; and

4. The learning environment due to the linkage provided more opportunities for student collaboration, leading to more effective learning and higher productivity.

These benefits satisfy recommendations made by mathematicians and statisticians concerning preparation of students for entry level statistics and mathematics courses. ${ }^{4}$

In this paper, we describe spreadsheet modeling of various finite mathematics applications designed to solve large scale problems that more closely resemble service- learning problems. Each spreadsheet model is used to reinforce concepts taught in the linked mathematics and technology classes and to help student teams learn how to develop such spreadsheet skills needed for the completion of organizational projects. Furthermore, spreadsheet modeling links and integrates mathematics and technology courses. Through demonstration of mathematical concepts using Excel spreadsheets, we stress synergies between mathematics, technology, and service-learning applications. These synergies emphasize learning goals such as quantitative skill development, analytical and critical thinking, information technology and technological issues, innovative and creative reasoning, and writing across the curriculum. ${ }^{5}$

\section{FINITE MATHEMATICS CONCEPTS AND SERVICE-LEARNING PROJECT MODELING USING EXCEL}

In a standard finite mathematics course offered for entry level students, students are introduced to topics such as, descriptive statistics and elementary data analysis; counting methods; probabilities including simple, conditional, Bayesian, etc.; systems of linear equations; matrices; systems of linear inequalities; and modeling and optimization problems including linear programming, and the simplex method. In teaching a topic the following sequence of steps takes place:

\section{Introduce a problem;}

\footnotetext{
${ }^{3}$ At Indiana University South Bend, each faculty member receives teaching credit for his/her discipline course when he/she teaches a linked course.

${ }^{4}$ See $[3] ;[23]$ and [25].

${ }^{5}$ The organizational projects, whose scope requires the use of computer technology skills, link the two courses. Evaluation of the students' learning consists of traditional exams in disciplines, industrial projects, and individual projects. In the mathematics course $44 \%$ of the student's grade is for traditional examinations, $40 \%$ for team organizational projects, $8 \%$ for individual projects, and $8 \%$ for portfolio, attendance, etc. In the technology course $70 \%$ of the student's grade is for traditional examinations, $22 \%$ for projects, and $8 \%$ for portfolio, attendance, etc.
}

2. Model the problem;

3. Explore multiple approaches to solve the model;

4. Apply algebraic skills while applying a method;

5. Translate the quantitative solutions into meaningful arguments within the context of the original problem;

6. Generalize the model;

7. Apply the method to other problems with other subject matters.

Each topic is practiced by students using small scale problems found in the textbooks and worked out manually. Such small scale problem solving is intended to help students learn and understand the basic principles underling the concepts. However, as discussed earlier, students, in general, consider such textbook type problems artificial and unrelated to service-learning problem solving. Most service-learning situations require defining the problem, data gathering, discovering the appropriate modeling techniques sufficient to solve the problem. Often times such sophisticated modeling techniques require large scale calculations that cannot be done manually. This is the case with the service projects used in the finite mathematics class. ${ }^{6}$. Given that virtually all students have access to computers and take at least one basic computer technology course, it is beneficial to teach linked finite mathematics and computer technology courses. In computer technology part of the linkage, we teach various packages including Microsoft Excel which becomes a modeling and technology environment that allows students to see that with even basic computer spreadsheet skills they can solve large scale service-learning problems. The following demonstrations highlight how Microsoft Excel can be used to enhance learning in both finite mathematics and technology courses, as well as prepare students to tackle service-learning projects involving large, complex data bases; modeling; and cumbersome computations. In each demonstration we show the value of the demonstration to understanding the mathematics principles, the power of Excel as a data analysis and modeling tool, and its application in solving service-learning projects.

\section{CALCUlation OF DESCRIPTIVE STATISTICS USING EXCEL}

In the Indiana University system, as well as many other schools, finite mathematics is a prerequisite for most majors, especially business, public administration, social sciences, and some life science areas. As mentioned earlier, statisticians MPR (2002) articulate a set of goals for mathematics prerequisites including instilling an appreciation of the power of technology and developing skills necessary to use appropriate technology to solve problems. The servicelearning project orientation of Mathematics in Action necessitates that student teams gather, process, analyze, and report on data using various tools acquired in the mathematics and technology courses described above. Descriptive statistics provide a powerful learning tool to introduce students to basic data analysis and presentation, as well as prepare

\footnotetext{
${ }^{6}$ See the following articles describing the use of servicelearning projects: $[2] ;[5] ;[7] ;[8] ;[10] ;[11] ;[14] ;[17] ;[18]$; [26]; [29]; [30]; [34]; [38]; [43]
} 
Table 1: Portion of Sample Data Set for Generating Pivot Tables

\begin{tabular}{|c|c|c|}
\hline Person & Courier & Journal \\
\hline 1 & no & no \\
\hline 2 & yes & no \\
\hline 3 & yes & no \\
\hline 4 & yes & yes \\
\hline 5 & yes & yes \\
\hline 6 & no & yes \\
\hline 7 & no & yes \\
\hline 8 & yes & no \\
\hline 9 & no & no \\
\hline 10 & yes & no \\
\hline
\end{tabular}

Table 2: Excel Generated Pivot Table for Newspaper Example

\begin{tabular}{|l|lc|c|}
\hline Count of Persons & Journal & \\
\hline Courier & no & yes & Grand Total \\
\hline no & 355 & 258 & 613 \\
yes & 522 & 365 & 887 \\
\hline Grand Total & 877 & 623 & 1500 \\
\hline
\end{tabular}

them for theoretical topics such as probability distributions that could be used for modeling empirical data. Thus, we have found that descriptive statistics is a useful tool for introducing students to many of the upcoming topics in the course.

The mathematics component of the linked courses introduces students to central tendency, dispersion, histograms, and charts using textbook type examples and other examples from popular media (e.g., USA Today, local newspapers, Business Week, etc.) In the linked technology component, students are instructed on how to use Excel spreadsheets to produce the same measures using service-learning actual data bases comparable to those they will work on in their service-learning projects. Such data typically come from personnel data bases that include various characteristics of employees such as gender, schooling, experience, title, salary. ${ }^{7}$ We also have generated data bases comparable to those found in various student service-learning projects completed in previous semesters. As an illustration, for example, we created a data set comparable to a similar data base analyzed by a student-team for a local newspaper. The data we generated refer to a situation where 1,500 individuals were randomly called concerning whether they subscribed to the Courier, the Journal, or both newspapers. The first ten observations of that data set are shown in Table 1

This example was used to demonstrate the ability of Excel spreadsheets to take a reasonably large data set and summarize it into a contingency table that can be used to calculate simple and conditional probabilities. Specifically, Excel's pivot table function cross classifies the 1,500 observations as shown in Table 2.

Based on this pivot table, students answer questions such as: What is the probability a randomly selected person sub-

\footnotetext{
${ }^{7}$ Many of these data bases are found in the textbook used in the computer technology course.
}

Table 3: Portion of Loan Analysis Project Data

\begin{tabular}{|l|r|r|r|r|}
\hline member no & acct no & balance & daysdel & prod code \\
\hline 4001026 & 155 & 8090.38 & 60 & 3 \\
\hline 5001026 & 156 & 9999.99 & 37 & 3 \\
\hline 3201027 & 145 & 5343.35 & 46 & 41 \\
\hline 6601087 & 166 & 10046.19 & 31 & 60 \\
\hline 7772032 & 145 & 7662.47 & 15 & 35 \\
\hline 1242420 & 155 & 202.18 & 10 & 5 \\
\hline 9722423 & 155 & 4627.82 & 15 & 6 \\
\hline 5822551 & 141 & 672.76 & 31 & 50 \\
\hline 3072551 & 155 & 6153.57 & 7 & 5 \\
\hline
\end{tabular}

scribes to the Courier $(887 / 1500)$ ? Similarly, what is the conditional probability that a subscriber to the Courier, also subscribes to the Journal (365/887)? Based on this pivot table, students are instructed how to construct tree and Venn diagrams which are useful in describing intersection and unions which underlie the Bayesian formula.

Excel 2007 provides a Venn diagram which helps a user convert the Pivot table into a graphic form. The following example converts the data in Table 2 into the Venn diagram shown in Figure 1.

This Venn diagram helps students visualize concepts such as union, intersection, and conditional probabilities.

As part of the instruction in descriptive statistics, students also make frequency distributions. Most textbook examples employ relatively small data bases (e.g. usually fewer than 50 observations) so that the frequency distributions can be made manually using tallying methods. Service-learning projects usually involve data sets consisting of large numbers of observations making manual approaches time consuming and subject to error. For example, in one of our service-learning projects for a local bank concerning delinquent loans, each month's delinquent loan data base contained approximately 7,000 loans, all in different stages of delinquency. A small segment of that data base is given in Table 3.

Table 3 contains 10 of the 6904 delinquent accounts. The first two columns represent the member number (which we have modified for security reasons) and the loan number. The next two columns contain the loan amount and days delinquent, and the final column contains a product code (e.g. auto, personal, home, etc.). Students were instructed on how to create a frequency distribution using Excel. Part of the instruction involved selecting meaningful intervals. After discussions with the client-bank, intervals of 1 to 30, 31-60, etc. were selected. Excel's Frequency function generated Table 4.

Excel requires as inputs the upper level of each interval (bins) with an empty interval capturing all observations greater than the largest interval. The format of the Excel output is not very meaningful for a general audience. Students thus are instructed to modify the Excel generated table to clarify the information. Table 5 represents a more user friendly version of Table 4 .

Furthermore, the same example is used to produce the histogram shown in Figure 2.

As illustrated in Table 6 , the above examples can easily be extended to introduce basic empirical probability concepts which can be easily computed from either the frequency dis- 


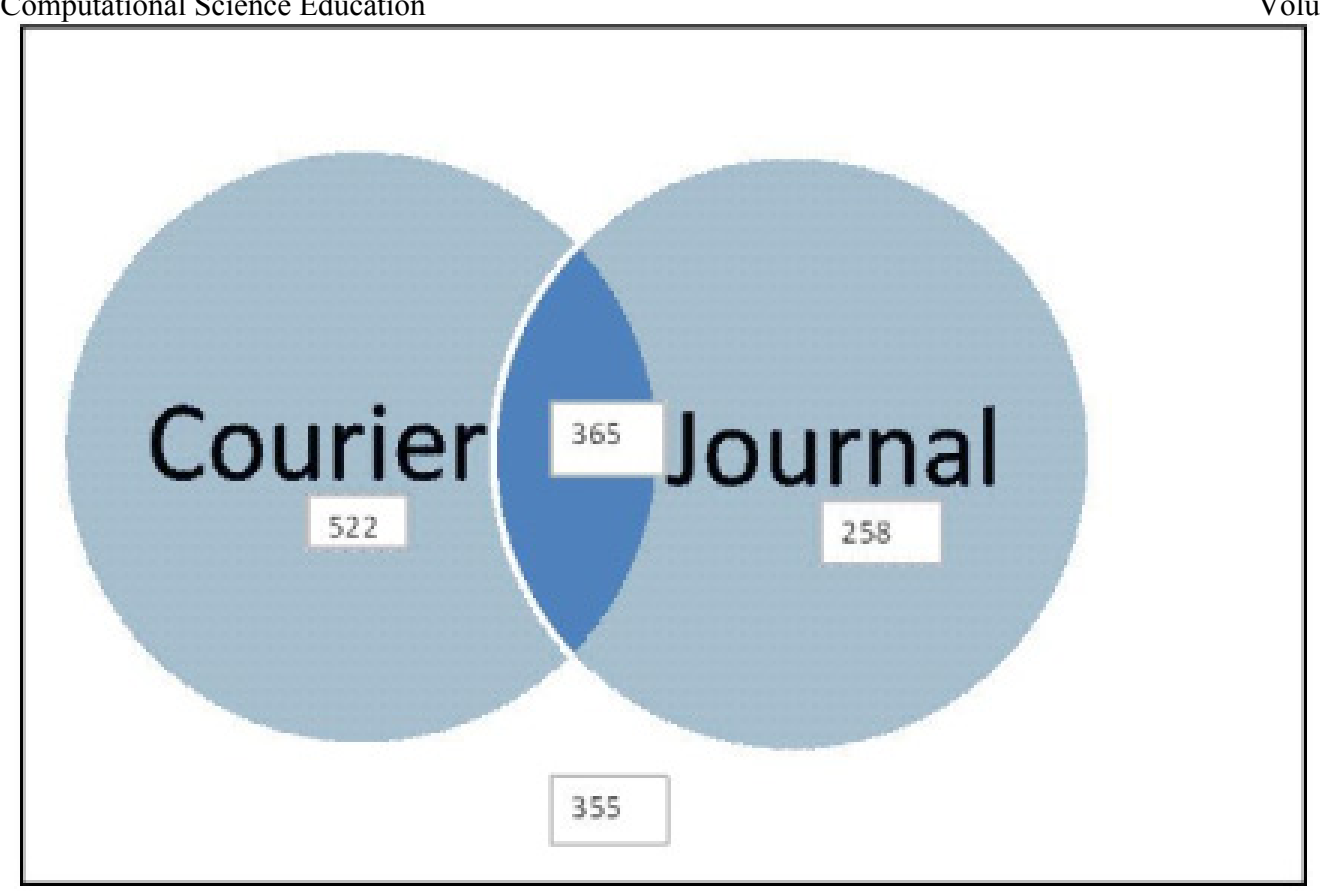

Figure 1: Excel Generated Venn Diagram Based On Pivot Table

Table 4: Excel Generated Frequency Distribution from Loan Analysis Data

\begin{tabular}{|r|r|}
\hline bins & Number \\
\hline 30 & 3739 \\
\hline 60 & 2082 \\
\hline 90 & 466 \\
\hline 120 & 220 \\
\hline 150 & 112 \\
\hline 180 & 96 \\
\hline & 189 \\
\hline Total & 6904 \\
\hline
\end{tabular}

Table 5: Reformatted Excel Frequency Distribution

\begin{tabular}{|r|r|}
\hline $\begin{array}{c}\text { Days } \\
\text { Deliquent }\end{array}$ & Frequency \\
\hline $0-30$ & 3739 \\
$31-60$ & 2082 \\
$61-90$ & 466 \\
$91-120$ & 220 \\
$121-150$ & 112 \\
$151-180$ & 96 \\
over 180 & 189 \\
\hline Total & 6904 \\
\hline
\end{tabular}

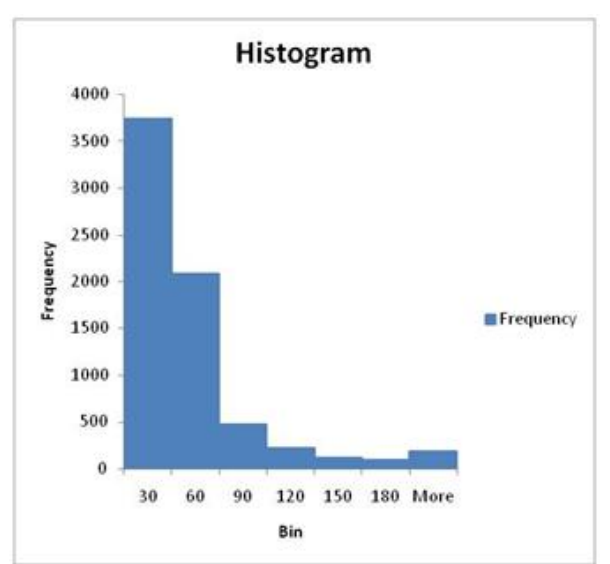

Figure 2: Histogram Based On Bank Loan Frequency Distribution 
Table 6: Empirical Probabilities Calculated from Excel Frequency Distribution

\begin{tabular}{|r|r|r|}
\hline $\begin{array}{c}\text { Days } \\
\text { Deliquent }\end{array}$ & $\begin{array}{c}\text { Empirical } \\
\text { Frequency }\end{array}$ & Probabilities \\
\hline $0-30$ & 3739 & 0.542 \\
$31-60$ & 2082 & 0.302 \\
$61-90$ & 466 & 0.067 \\
$91-120$ & 220 & 0.032 \\
$121-150$ & 112 & 0.016 \\
$151-180$ & 96 & 0.014 \\
over 180 & 189 & 0.027 \\
\hline Total & 6904 & 1.000 \\
\hline
\end{tabular}

tribution or the histogram.

This example can be further used to illustrate generating research questions and answering such questions with contingency tables and tree-diagrams. An example based on the loan data is given in Table 7 and Figure 3.

Contingency Table 7 was produced using the Pivot function discussed earlier to answer a research question about whether the bank anticipates slow paying borrowers by charging a higher interest rate on the loan. The answer is clearly yes. For instance, the simple probability of a loan being bad (loans being delinquent more than 30 days) is .0103. However, for customers receiving the very lowest rates, and presumably judged to be the best credit risk, the probability of a bad loan is virtually zero. In contrast, for customers paying the very highest rates, and again presumably judged to be poor credit risks, the probably of a bad loan increases to 0.0296 , almost triple the simple probability of a bad loan. Continuing with this example, one also can produce the tree diagram given in Figure 3.

Given information about the rate a borrower pays, Bayes Theorem can be used in conjunction with either the above Table 7 or the tree-diagram given in Figure 3 to find the probability that the loan is either good or bad. For instance, the student-team working on this service- learning project observed that the contingency table and the calculations from Bayes formula using information in the tree-diagram agreed, namely that when the bank charged a rate greater than 10 percent, the probability that the loan ultimately would be bad was 0.0296 . We found it to be very successful as a teaching approach to employ multiple approaches to illustrating complex topics, such as Bayes Theorem.

In addition to the Pivot Table function described above, Excel's filtering and sorting capabilities make it possible using a large data base to investigate research questions related to how customer and/or loan characteristics contribute to defaults. In the local bank service-learning project described above, the client was interested in the characteristics of customers, loans, or both that contributed to higher delinquency probabilities. This led the student team to sort and filter the data. The student team used Excel to sort selected data by loan size to investigate the characteristics of delinquent loans based on whether they were large, medium, or small. Also, the student-team filtered the data by product type (e.g., car loans, personal loans, home mortgages, and the like) to see whether loan delinquency probabilities depended on loan type. Further, the student-team filtered the data by the income of loan recipients, as well as their credit report characteristics (e.g., credit score, number credit cards, past delinquent accounts, and the like). This filtering and sorting provided a powerful tool for preliminary causal analysis of the determinants of loan delinquency rates that might be used as a decision tool for designing future lending products and offering loans to future potential customers.

\section{PERMUTATIONS AND COMBINATIONS}

As an introduction to probabilities, students are introduced to basic counting methods. Combinations and permutations represent a universal counting approach. The computations for these techniques can be quite cumbersome. Although some more advanced hand held calculators provide options for calculating combinations and permutations, they are, nonetheless, much easier using Excel. In addition, most students once they start working will have more access to Excel than to any other means of computing. Excel provides formulas that can be inserted into a document so that repetitive computations can be quickly made. Part of the teaching in finite mathematics involves practicing the use of the formulas for combinations and permutations. We use various examples related to selecting, for example, 3 persons from a group of 10 to serve on a committee. One type of selection is where the order of selection is not important; the alternative selection makes the first person president, the next vice president, and third treasurer. Students learn the combination and permutation formulas to calculate the number of possible selections in each case. Furthermore, these numbers could be used for calculating probabilities, such as the probability that a three-person selection would have at least one female or that a particular arrangement happens. There are many other applications related to quality control, gambling, statistical sampling, and the like.

The Excel example given in Figure 4 attempts to interconnect what students learn in the mathematics class and what Excel's spreadsheet provides in terms of a computational environment.

As shown in Figure 4, there are 254, 251, 200 permutation and 2,118,760 combinations of five items taken out of a total 50 are calculated. By simply changing the number of objects and number of objects to be selected in the upper left hand box, students can quickly find permutations and combinations. These formulas have direct application in determining probabilities such as quality control problems. A common problem (using the techniques shown in Figure 4) given in our textbook asks the probability of having defective calculators in a sample of five chosen from a box of 30 calculators purchased by a school of which historically 10 percent are defective. The easiest way to solve this is to use the complementary problem which calculates the probability of no defectives in a sample of five and then subtracts this result from one. In terms of the formulas defined in Figure 4, the probability is obtained as:

$$
\begin{aligned}
P_{(\text {at least } 1 \text { defective from a sample of 5) }} & =1-P_{(0 \text { defectives })} \\
& =1-\frac{C_{27,5}}{C_{30,5}} \\
& =1-\frac{80,730}{142,506}=0.433
\end{aligned}
$$

where $C_{27,5}$ is the number of samples of size 5 with no 
Table 7: Research Questions Formulated From Excel Loan Analysis Pivot Table

\begin{tabular}{|c|c|c|c|c|c|}
\hline \multicolumn{6}{|c|}{$\begin{array}{l}\text { Research Question: Is there a relationship between } \\
\text { the annual percentage rate and days delinquent? }\end{array}$} \\
\hline & & \multicolumn{4}{|c|}{ Annual Percentage Rate } \\
\hline & & $<5$ & $>=5<10$ & $>=10$ & Total \\
\hline \multirow{3}{*}{ Days Delinquent } & Good & 24 & 12706 & 4859 & 17589 \\
\hline & Bad & 0 & 35 & 148 & 183 \\
\hline & Total & 24 & 12741 & 5007 & 17772 \\
\hline $\mathrm{P}($ Good $)$ & \multicolumn{2}{|c|}{0.989703} & \multicolumn{2}{|l|}{$\mathrm{P}(\mathrm{Bad})$} & 0.0103 \\
\hline $\mathrm{P}($ Good $\mid<5)$ & \multicolumn{2}{|c|}{1.000} & $\mathrm{P}(\mathrm{Bad} \mid<5$ & & 0.000 \\
\hline $\mathrm{P}(\operatorname{Good} \mid>=5<10)$ & \multicolumn{2}{|c|}{0.9973} & \multicolumn{2}{|c|}{$\mathrm{P}(\mathrm{Bad} \mid>=5<10)$} & 0.0027 \\
\hline $\mathrm{P}(\operatorname{Good} \mid>=10)$ & \multicolumn{2}{|c|}{0.9704} & \multicolumn{2}{|c|}{$\mathrm{P}(\mathrm{Bad} \mid>=10)$} & 0.0296 \\
\hline
\end{tabular}

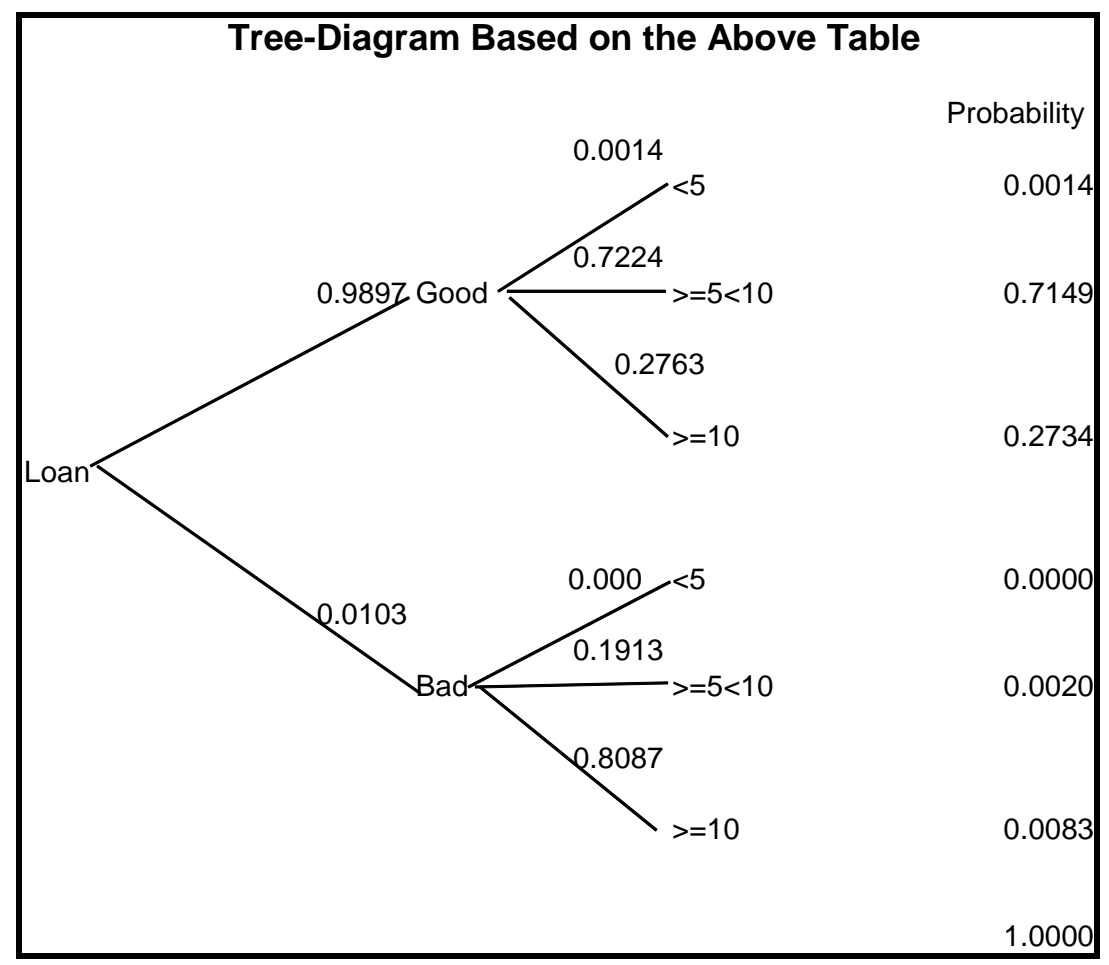

Figure 3: Tree-Diagram Based On Excel Pivot Table 


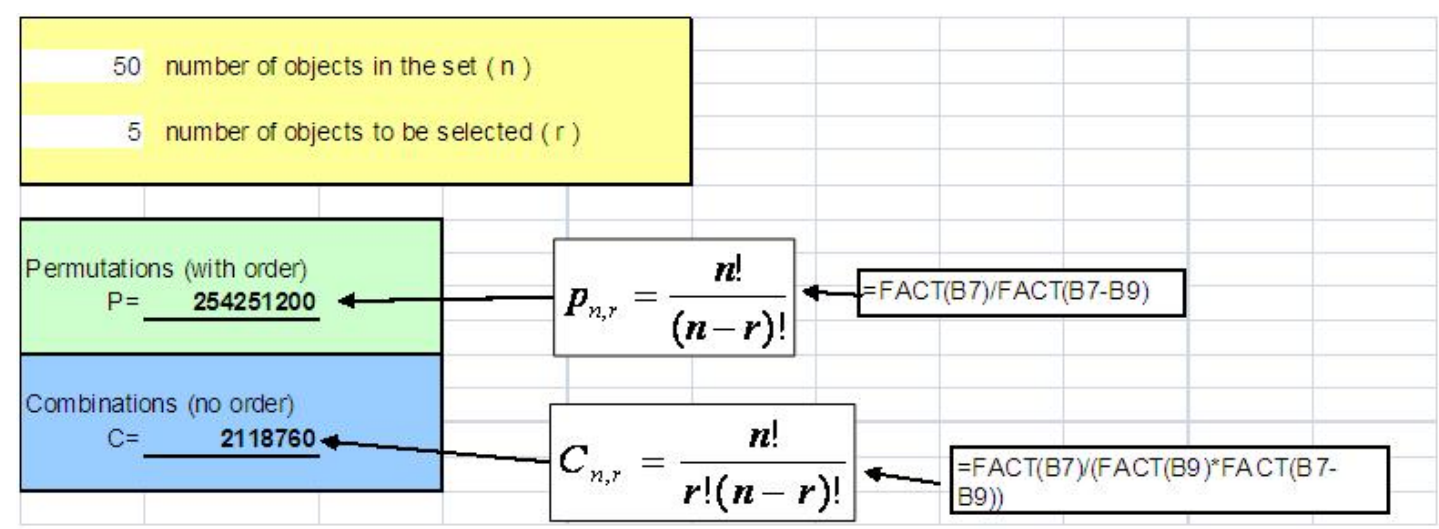

Figure 4: Excel Calculations of Permutations And Combinations

defective calculators and $C_{30,5}$ is the number of samples of size 5 from the population of 30 . There are many other similar quality control problems as well as classical examples using decks of cards (e.g., the probability of obtaining a "fullhouse" in a five card poker hand).

The use of combinatorial techniques played a role in helping students understand one of our earliest service-learning projects that dealt with finding the most efficient lunch delivery routing system for a local school system, a classic Traveling Salesperson problem. Resources became routes between school buildings, costs distances of these routes, with the objective to minimize the total cost of the route. Constraints required that each location be visited once and only once. The analysis required the student-team to gather information on distances (or travel times) between various school buildings for the school corporation's internal delivery system.

We created a simplified version of the problem, for instance for four cities, so that they could see just what was involved. For example, suppose a salesperson starts from a corporation in Chicago and wants to visit the cities South Bend, Indianapolis, and Michigan City. Distances between these cities are found in Table 8 .

Combinatorial method calculations indicate that there are six possible paths listed in Table 9 , for each path the distance was calculated by hand from data in Table 8.

The optimal solution are the following routes with the minimum distance 375 miles (Chicago, to Michigan City, to Indianapolis, to South Bend, returns to Chicago. Alternatively, follow this path in the reverse order).

Chicago, to Michigan City, to Indianapolis, to South Bend, returns to Chicago. Alternatively, follow this path in the reverse order.

We used Excel to demonstrate to the students that as the number of destination points increased the permutations that would require evaluation became extremely large. For illustration, if there are 12 points instead of 4 points, the combinatorial solution will involve 11 ! or $39,916,800$ possible patterns which are too many to evaluate manually.

Our Excel demonstrations using combinatorial techniques led students to investigate other more efficient solution algorithms such as binary programming and Excel's solver module.

\section{SIMULATION OF STOCHASTIC PROCESSES}

In teaching probability concepts, students often confuse theoretical and empirical probabilities. For example, the probability of a head when tossing a fair coin is 0.50 while tossing a fair coin 100 times may lead to far more or far fewer than 50 heads, perhaps even as many as 70 or as few as 30. Most students perceive that a theoretical probability of 0.5 means that nearly (if not exactly) 50 of the 100 flips should be heads. Such confusion can be dealt with by setting up experiments that compare empirical and theoretical probabilities. Prior to using Excel, we had each student toss a coin 10 times and tallied results for all students. The procedure is both time consuming and limited to a small number of tosses. For efficiency and flexibility, we use the power of Excel to simulate stochastic processes. The example used for illustration is that of rolling a six-sided die 1000 times. Once the spreadsheet is setup we can simulate 1000 rolls (or any other number) over and over and then compare the empirical outcomes to the theoretical probabilities. The same procedure could be used for tossing coins, rolling more than one die, dealing card hands, spinning of a roulette wheel, and the like. ${ }^{8}$ In the illustration shown below, in addition to having Excel simulate the roll of a die 1000 times we also construct a frequency distribution and histogram of outcomes to facilitate comparison of empirical and theoretical probabilities. The simulation output displayed in Table 10 is produced by using the formulas $\operatorname{ROUNDDOWN}(6 * \operatorname{RAND}(), 0)+1$ and FREQUENCY (C4:C1003,F4:F9), where C4:C1003 contain the 1000 randomly generated die numbers and F4:F9 hold the die values 1 through 6 .

By hitting the F9 key in Excel, students see how each outcome of 1000 rolls differs from each other and from the theoretical probabilities. This simulation would provide tools for more advanced discussions of stochastic processes dealing with the law of large numbers, the central limit theorem, confidence intervals, and the like.

A number of our service-learning projects involved stochastic processes. In one such service-learning project, students were asked to make recommendations on whether it would

\footnotetext{
${ }^{8}$ As the number of trials increases, the empirical probability distributions converge to the theoretical distributions.
} 
Table 8: Hypothetical Traveling Salesperson Routing

\begin{tabular}{|ccccc|}
\hline & 1-Chicago & 2-South Bend & 3-Michigan City & 4-Indianapolis \\
\hline 1-Chicago & 0 & 90 & 60 & 150 \\
2-South Bend & 90 & 0 & 40 & 135 \\
3-Michigan City & 60 & 40 & 0 & 160 \\
4-Indianapolis & 140 & 130 & 160 & 0 \\
\hline
\end{tabular}

Table 9: Possible Routing Patterns Based On Hypothetical Example

\begin{tabular}{lc}
\hline Route & Total Distance \\
\hline $1-2-3-4-1$ & 440 \\
$1-2-4-3-1$ & 445 \\
$1-3-2-4-1$ & 375 \\
$1-3-4-2-1$ & 445 \\
$1-4-2-3-1$ & 375 \\
$1-4-3-2-1$ & 440 \\
\hline
\end{tabular}

Table 10: Excel Simulation of Rolling A Die 1000 Times

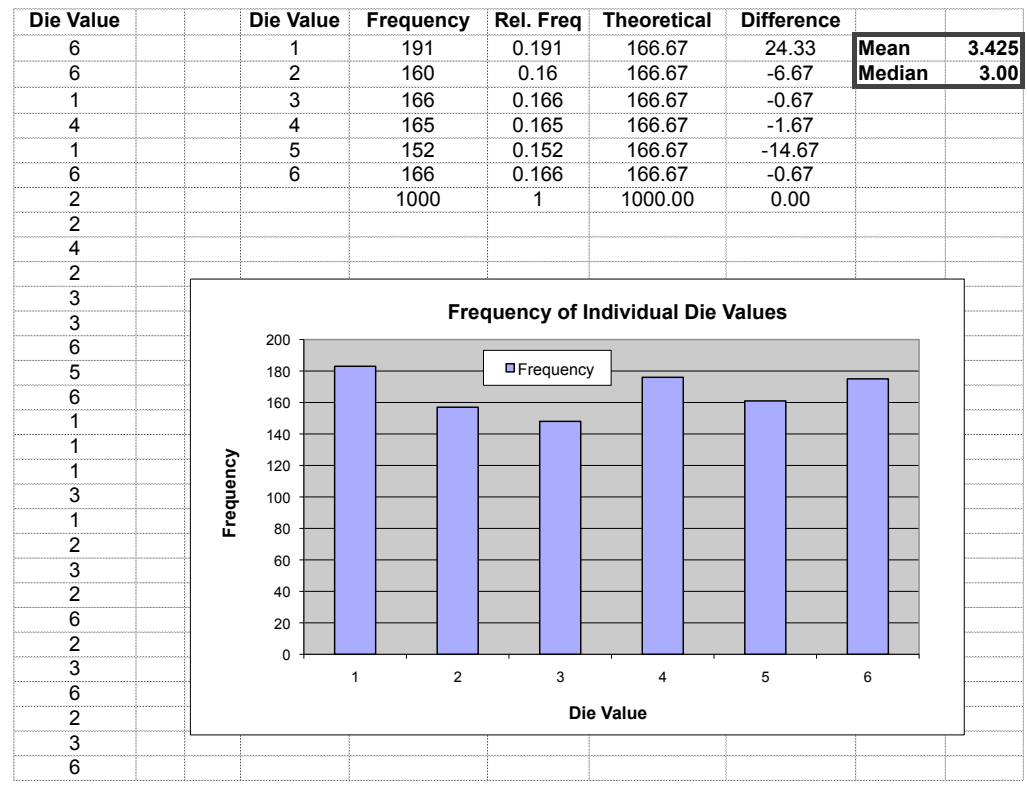


be less costly to change light bulbs in an elementary school as they burned out or to periodically change all the lights in the school at the same time. The hours of life of a light bulb follows a stochastic process generally modeled with the exponential distribution. For example, a florescent light bulb, with an expected life of 30,000 hours, has a cumulative probability distribution given in Figure 5 where the horizontal axis represents the life of a bulb.

The student-team working on this project recognized the tradeoff between higher maintenance costs if bulbs are replaced as they burn out versus higher light bulb costs if bulbs are all replaced at the same time. The stochastic bulb life process suggested that about 10 percent of the bulbs would have a life of approximately 4,000 hours. If 10 percent burnt out bulbs was an upper limit on the acceptable number of bulbs burnt out at any one time, then about 90 percent of the bulbs would be discarded far before they burned out. Indeed, about one-half of the bulbs would last more than 20,000 hours. The students thus estimated the costs of the two strategies and concluded that "Taking into consideration the amount of money that would be lost with the implementation of any of these total bulb-changing policies, we recommend that the [the client] continue their current policy of changing light bulbs on an as-needed basis."

\section{MODELING OPTIMIZATION PROBLEMS WITH CAPACITY CONSTRAINTS}

A key concept students learn in the linked finite mathematics and technology courses is the value of solving constrained optimization problems. Not only are these concepts and solution techniques valuable to business and economics students, but they also play important roles in several of the service-learning projects undertaken by student teams. As an illustration, a student-team applied constrained optimization techniques to find an optimal mix of fund raising activities for a local chapter of the American Diabetes Association (ADA). Basically, the local ADA director had limited resources such as working capital, hours of volunteer time, restrictions on her own time, frequency of certain types of fund raising events (e.g., only so many fund raising walks can take place in a given year), and the like. The student team undertaking this project gathered data on estimated revenues from each event, as well as the amount of working capital, volunteer time, etc. each event required. After solving the problem for the optimal portfolio of events, students then performed post- optimality sensitivity analysis influenced by weather conditions. Fundraising walks, for example, raise much smaller amounts on cold unpleasant days than under more favorable conditions. The student team indentified three possible post-optimality scenarios: 1) normal (average) weather conditions; 2) exceptional (above average) weather conditions; and 3) severe (below average) weather conditions. Other student teams also applied these techniques to optimal land allocation for a mall parking lot, optimal use of full-time v. part-time workers for a local school corporation, optimal routing for a school corporation lunch delivery program (the traveling salesperson problem mentioned above), and the optimal keep v. replacement policy for school corporation trucking equipment.

As part of the curriculum, we teach students the mathematics behind optimization with various capacity constraints as well as how to model such problems using Excel spread- sheetss and the Excel solver module. For example, we use problems from our course textbook ${ }^{9}$. One such problem is given below: Construction-resource allocation. A contractor is planning to build a new housing development consisting of colonial, split-level, and ranch-style houses. A colonial house requires $1 / 2$ acre of land, $\$ 60,000$ capital, and 4,000 labor-hours to construct, and returns a profit of $\$ 20,000$. A split-level house requires $1 / 2$ acre of land, $\$ 60,000$ capital, and 3,000 labor-hour to construct, and returns a profit of $\$ 18,000$. A ranch house requires 1 acre of land, $\$ 80,000$ capital, and 4,000 labor-hours to construct, and returns a profit of $\$ 24,000$. The contractor has available 30 acres of land, $\$ 3,200,000$ capital, and 180,000 labor-hours.

A How many houses of each type should be constructed to maximize the contractor's profit? What is the maximum profit?

B A decrease in demand for colonial houses causes the profit on a colonial house to drop from $\$ 20,000$ to $\$ 17,000$. Discuss the effect of this change on the number of houses built and on the maximum profit.

C An increase in demand for colonial houses causes the profit on a colonial house to rise from $\$ 20,000$ to $\$ 25,000$. Discuss the effect of this change on the number of houses built and maximum profit.

Prior to solving the problem, students are shown how to model the problem in an Excel spreadsheets. Table 11 displays the organizational spreadsheet for part B of the problem.

The spreadsheet includes formulas that sum up the products of the decision variables and per unit resource usage amounts as well as total profits. For example, the total usage of land is computed using the Excel formula SUMPRODUCT (F6: H6, $\$ \mathrm{E} \$ 16$ : $\$ \mathrm{G} \$ 16$ ); where F6: H6 are cells containing per unit land resources for colonial, split- level, and ranch homes, respectively, and where E16:G16 represent the numbers of each type of produced house. This model allows us to discuss trial and error approaches to solving the feasible and optimal mix of houses. For example, the spreadsheet in Table 12 shows the profits and resource utilization for producing 20 of each type of house. Although total profits are high, the solution is not feasible since all of the capacity constraints are violated. The spreadsheet model makes it very easy to test numerous combinations of the three types of houses and to discuss whether or not they are feasible. Even when feasible outcomes are obtained there is no insurance that these outcomes are optimal. Students quickly learn that a trial and error approach which could conceivably list every possible outcome is not only time consuming but very inefficient. Besides exploring the solution to this problem using the Simplex Method and graphical techniques, we teach students in the technology course how to use the Excel solver to find the optimal solution.

Numerous other examples are used dealing with manufacturers, nutrition, portfolio allocation, and the like. An example showing the entire Excel spreadsheets formulation for minimizing the transportation cost taking students and chaperones on a trip by two different means of transportation is found in Figure 6.

\footnotetext{
${ }^{9}$ See [1], problem 43, p. 314.
} 


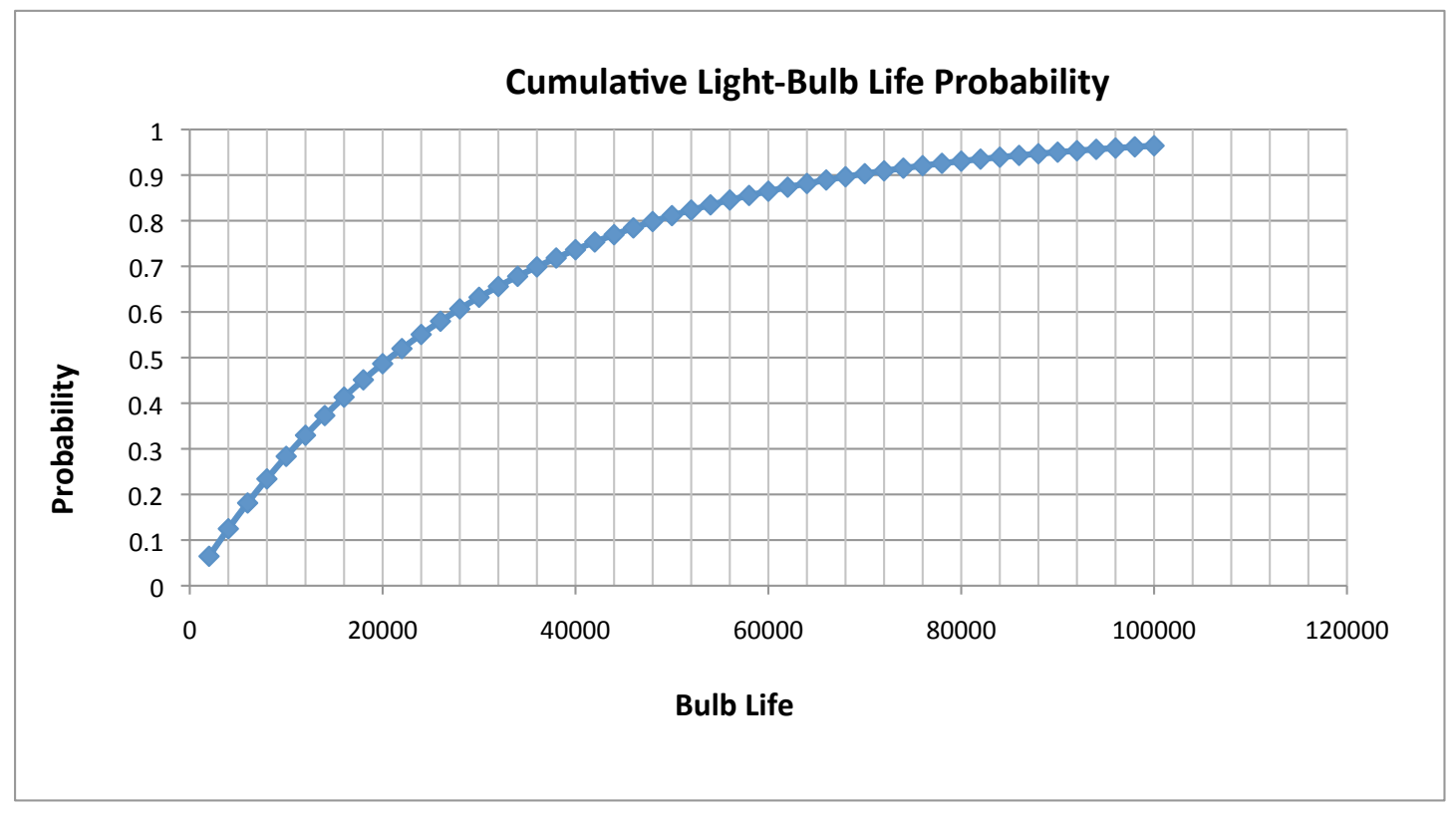

Figure 5: Excel Generated Exponential Probability Distribution

Table 11: Excel Spreadsheets for Modeling Linear Programming Problem

\begin{tabular}{|c|c|c|c|c|c|c|}
\hline & $\mathrm{C}$ & S & $\mathrm{R}$ & USEAGE & & CAPACITY \\
\hline LAND PER HOUSE (ACRES) & 0.5 & 0.5 & 1 & 0 & $<=$ & 30 \\
\hline LABOR PER HOUSE (HOURS) & 4000 & 3000 & 4000 & 0 & $<=$ & 180000 \\
\hline CAPITAL PER HOUSE (\$) & 60000 & 60000 & 80000 & 0 & $<=$ & $\$ 3,200,000$ \\
\hline PROFITS PER HOUSE & $\$ 17,000$ & $\$ 18,000$ & $\$ 24,000$ & \multirow{3}{*}{\multicolumn{2}{|c|}{$\begin{array}{l}\text { TOTAL PROFIT } \\
\quad \$ 0\end{array}$}} & \\
\hline ACTIVITIES & NO.C & NO.S & NO.R & & & \\
\hline DECISION VARIABLES & 0 & 0 & 0 & & & \\
\hline
\end{tabular}

Table 12: Excel Trial and Error Demonstration of the Construction Problem

\begin{tabular}{|c|c|c|c|c|c|c|}
\hline & $\mathrm{C}$ & $\mathrm{S}$ & $\overline{\mathrm{R}}$ & USEAGE & & CAPACITY \\
\hline LAND PER HOUSE (ACRES) & 0.5 & 0.5 & 1 & 40 & $<=$ & 30 \\
\hline LABOR PER HOUSE (HOURS) & 4000 & 3000 & 4000 & 220000 & $<=$ & 180000 \\
\hline CAPITAL PER HOUSE (\$) & 60000 & 60000 & 80000 & 4000000 & $<=$ & $\$ 3,200,000$ \\
\hline PROFITS PER HOUSE & $\$ 17,000$ & $\$ 18,000$ & $\$ 24,000$ & \multirow{3}{*}{\multicolumn{2}{|c|}{$\begin{array}{l}\text { TOTAL PROFIT } \\
\$ 1,180,000\end{array}$}} & \\
\hline ACTIVITIES & NO.C & NO.S & NO.R & & & \\
\hline DECISION VARIABLES & 20 & 20 & 20 & & & \\
\hline
\end{tabular}




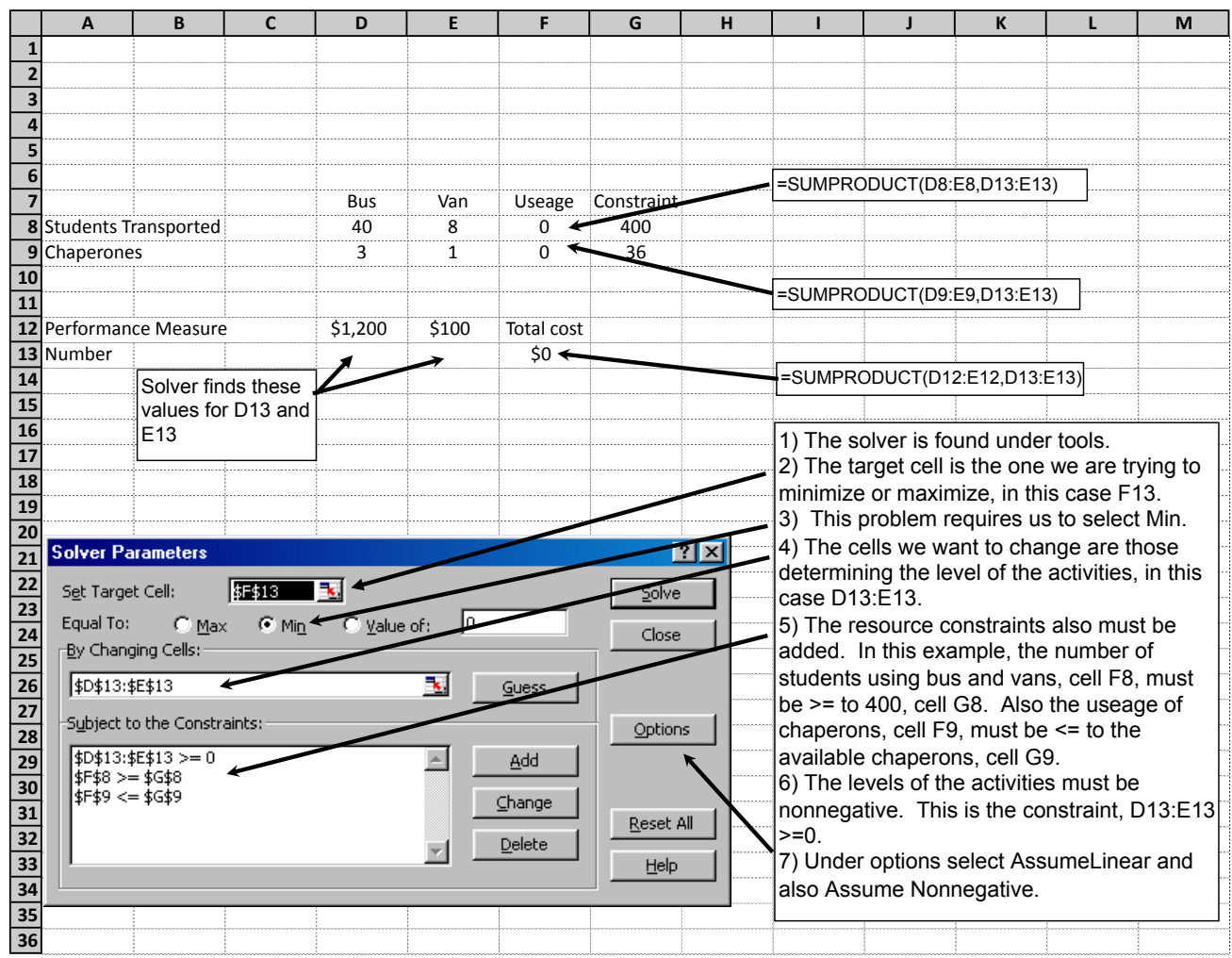

Figure 6: Excel spreadsheets for Solving Transportation Example

Table 13: Excel Solver Module Solution to Ada Event Mix Problem

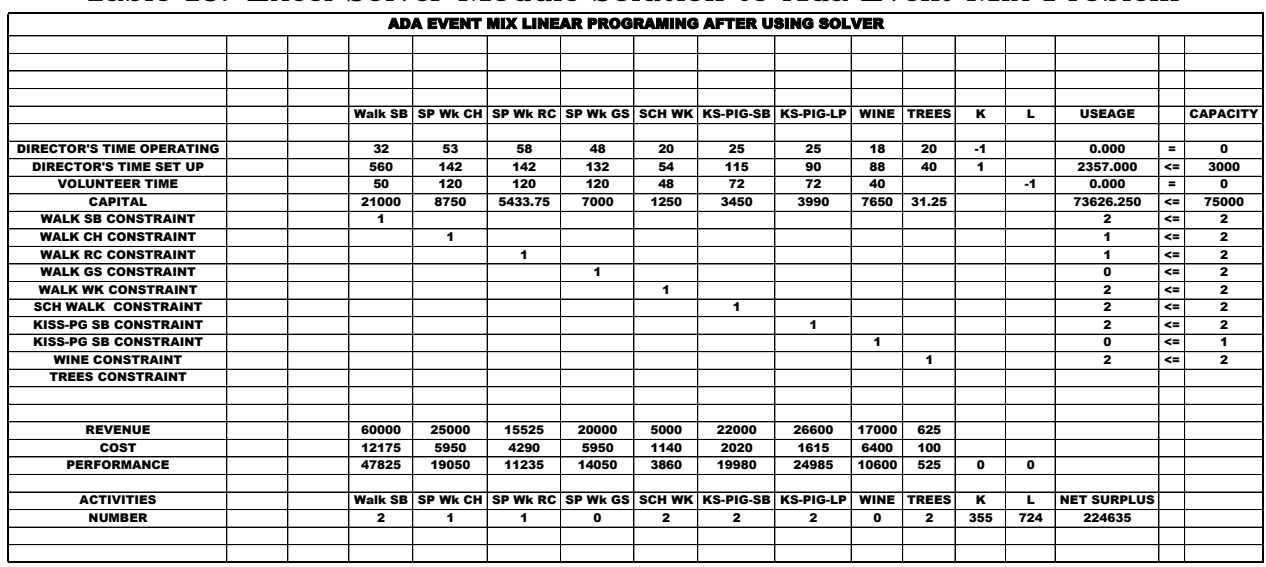


The American Diabetes Association example mentioned above provides an excellent example of how students can generalize the Excel examples to a service-learning project. After collecting the appropriate data and using Excel's solver, the student-team working on this project generated the output found in Table 13 .

Given the various constraints on the director's time, volunteers' time, working capital, and the maximum number of times an event could be held in a given period, the studentteam was able to recommend the mix of fundraising events that would maximize the net fundraising surplus (e.g., two $\mathrm{SB}$ walks, one spring walk $\mathrm{CH}$, one spring walk $\mathrm{RC}$, etc.). In addition, the student-team was able to test the sensitivity of the outcomes to various assumptions about weather conditions and therefore introduce a stochastic element into their recommendations.

\section{CONCLUSIONS}

The Excel demonstrations given above promote synergies between mathematics, technology, and applied research. We have found that students enjoy the hands-on nature of the Excel software and engage with it enthusiastically in working on their service-learning projects. Indeed, student comments such as those given below attest to the strong appeal this approach offers. ${ }^{10}$

"We actually got to use things like probability and frequency tables and see that it worked. We were not just taking a test."

"I don't have a fear of math now. I understand where you can utilize it in everyday life."

"I was never really good in math, this course gave me courage; I'm not afraid of it anymore. I felt safe and secure in coming to class... This type of class would have a whole generation of people loving math."

"We got to work, every week or so, interactively with the business leaders, working on an active problem they are having with their business."

\footnotetext{
${ }^{10}$ The above comments are from students that were made in the students' course evaluation, an interview made by a grant administrator, and newsletters. Instructors were not present when these comments were made. Because the course was an experimental course attempting to demonstrate to beginning students the power of mathematics to solving service-learning projects, the National Science Foundation undertook in-depth qualitative evaluations of students. In addition, a School of Education colleague of ours also interviewed students concerning various aspects of their experience. The comments provided above are typical of these evaluations. The value of using Excel demonstrations enhanced the service-learning project reports and made possible sophisticated data analysis. For example, because of their acquired skills in using Excel, students were able to successfully complete service-learning projects such as the traveling-sales person problem, contingency table analysis of delinquent loans and borrower characteristics, linear programming solutions to fund-raising activities, probability distribution analysis leading to efficient light bulb replacement policies, and a host of other complex problems. Evaluators of the course thought these were extraordinary accomplishments for entry level students.
}

"This was a great hand-on experience that took my fear out of working within a business and handling specific problems and finding a solution where possible. It showed us that no matter what the problem is, there is a formula that can help to work it out for the best of the business and employees."

"Having a real -life problem to handle and solve left a more realistic impression of what the work world has to contend with to do the best job you can for your business, employees, and customers."

"I learned a lot about math as well as the business world."

"I like unique way of learning math and relating it to real world."

"I enjoyed working in a group to help solve a common problem. The hands-on experience of working in a real-life situated problem was a great opportunity to have. I truly appreciate the instructors, business and the developers of the program for allowing helping and encouraging us to perform at a higher level."

"I liked the hands-on, interactive projects we had to do. Having the availability of two professors and one tutor helped immensely. Doing the projects will solidify what I have learned."

The Excel demonstrations also appear to help students better grasp the mathematical principles underlying the demonstrations and to better appreciate the power of applied mathematics and statistics in investigating research questions using actual real-world data bases. The Excel applications directly achieve two of the goals mentioned earlier that statisticians propose for introductory mathematics classes: 1) use real, engaging applications through which students can learn how to draw connections between the language of mathematics and the context of the application; and 2) instill appreciation of the power of technology and develop skills necessary to use appropriate technology to solve problems, develop understanding, and explore concepts. It is our observation that students taking a course that links, mathematics, technology, and service-learning projects not only prepare themselves to undertake service-learning projects in their introductory mathematics course but further take away from their experiences mathematical, technological, and research skills that they then apply in their future courses in business and economics. Equally important, students leave the courses with a new appreciation of the power of mathematics and technology. This is the very outcome the National Science Foundation hoped for when funding servicelearning courses such as Mathematics in Action.

\section{REFERENCES}

[1] Barnett, R. A. And M. E. Ziegler. 2008. Finite Mathematics for Business, Life Sciences, and Social Sciences, 11th edition, Pearson/Prentice Hall, Upper Saddle River, New Jersey. 
[2] Bixby, J.A., J.R. Carpenter, P.L. Jerman, and B.C. Coull. 2003. Ecology on campus. Journal of College Science Teaching 32 (5): 327-331.

[3] Coвb, G.W. 1992 , "Report of the Joint ASA/MAA Committee on Undergraduate Statistics," Proceedings of the Section on Statistical Education American Statistical Association, 281-283.

[4] COMAP 2009. For All Practical Purposes, 8th Edition, W. H. Freeman and Co., New York.

[5] Engel, A., C.L. May, And M. O'Leary. 2005. "The Baltimore City Fire Department staffing problem." In Hadlock 2005, 35-46.

[6] Grinshpan, J.R. 2005. "The mathematics umbrella: Modeling and education." In Hadlock 2005, 47-58.

[7] Grossman, Julie, And Terrence Cooper. 2004. "Linking environmental science students to external community partners: A critical assessment of a service learning course." Journal of College Science Teaching 33 (5) (March-April): 1-5.

[8] Hadlock, Charles R. ed. 2005. Mathematics in Service to the Community: Concepts and Models for Service-Learning in the Mathematical Sciences. Mathematical Association of America, Washington, DC

[9] Hatcher T., Hinton B., ET. AL. 1996. Graduate Student's Perceptions of University Team Teaching. College Student Journal, Vol. 30, Issue 3, p. 367.

[10] Hydorn, Debra, L. 2005. Community service projects in a first statistics course. In Hadlock 2005, 111-122.

[11] ING, P.H. 2005. Designing efficient snow plow routes: A service-learning project. In Hadlock 2005, 69-80.

[12] Jerde, C.L. And M.L. TAPer. 2004. Preparing undergraduates for professional writing. Journal of College Science Teaching 33 (7): 34-37.

[13] Kochanowski, P. And Shafim-Mousavi, M. $2003 a$. Mathematics Preparation for First Statistics Courses. 2003 Proceedings, American Statistical Association. 2205-2212.

[14] Kochanowski, P. And Shafi-Mousavi, M. $2003 \mathrm{~b}$. Project Based Learning in an Interdisciplinary Economics and Mathematics Service Course. Midwest Business Economics Association Proceedings. 161-169.

[15] Kochanowski, P. And Shafin-Mousavi, M. 2000. How to Design and Teach a Project Based First-Year Finite Mathematics Course. UMAP Journal, COMAP, Vol. 21.1 Summer, p.119-138.

[16] Kochanowski, P. And Shafit-Mousavi M. 1998. Lessons Learned From Team Teaching an Interdisciplinary Introductory Course in Economics and Mathematics, Proceedings of the Mathematical Modeling in the Undergraduate Curriculum, University of Wisconsin - La Crosse, 1998.

[17] Maki, D., Winston, W., Shafit-Mousavi, M., Kochanowski, P., Lang, C., Ernstberger, K., And Hodgson 2005. On the Use of Client Projects in the Mathematics Classroom. Primus: Problems, Resources, and Issues in Mathematics Undergraduate Studies. United States Military Academy, West Point, New York 10996-9902 USA. Forthcoming.
[18] Massey, M. 2005. Service-learning projects in data interpretation. In Hadlock 2005, 123-130.

[19] McIntosh, M. And Johnson, D. L. 1994. An Instrument to Facilitate Communications between Prospective Team Teachers. Clearing House, Vol. 67 Issue 3, p. 152.

[20] McKelvey, S. 2005. Real-world consulting: The Saint Olaf mathematics program. In Hadlock 2005, 25-34.

[21] Michaelsen, L. K. 1999. Integrating the Core Business Curriculum an Experienced Based Approach. Selections, Winter, pp. 9-17.

[22] C. D. Miller, V. E. Heeren, And John Hornsby. 2004. Mathematical Ideas, 10th Edition, Pearson/ Addison Wesley, Boston, Massachusetts

[23] Moore, T., Peck, R., and Rossman, A. 2002. "Statistician Advise Mathematics Association on Undergraduate Curriculum," Amstat News.

[24] G. L. Musser, Burger W.F and Peterson B. 2008. Mathematics for Elementary Teachers, 8th Edition, John Wiley \& Sons Inc.

[25] O'Shea, D. and Pollatesek, H. 1997. "Do We Need Prerequisites?," Notices of the AMS, 564-570.

[26] Phillips, M.W. 1997. Teaching general biology for nonmajors through community projects. Journal of College Science Teaching 26 (4): 253-257.

[27] Poff, J.M., D. Larson, and C.F. Rodell. 2004. Biology of the Southwest. Journal of College Science Teaching 33 (6): 40-44.

[28] Ramsay, J.R. 2005. Creating experience in an experiential learning. In Hadlock 2005, 47-58.

[29] ReED, G. 2005. Perspectives on statistics projects in a service-learning framework. In Hadlock 2005, 83-88.

[30] Roberts, Catherine A. 2005. Perspectives on modeling applications in a service learning framework. newblock In Hadlock 2005, 13-24.

[31] Root, R., T. Thorme, and C. Gray. 2005. Making meaning, applying statistics. In Hadlock 2005, 89-100.

[32] SChrage, L. 1986 LINDO (Linear Interactive and Discrete Optimizer) LINGO. It is a user-friendly computer package that can be used to solve linear, integer, and quadratic programming problems.

[33] Shafi-Mousavi, M. And Kochanowski, P. 2006. "Integrating First-Year Technology And Finite Mathematics Courses". PRIMUS Problems, Resources, and Issues in Mathematics Undergraduate Studies, Vol. $X V I(1)$, pp. 61-80.

[34] Shafi-Mousavi , M. and Kochanowski, P. 2006 "Service-Learning Projects in Linked Mathematics and Computer Technology Courses," Umap, pp. 449-468.

[35] Shafit-Mousavi, M. and Kochanowski, P. 1999. The Use of Computer Technology in a First-year Finite Mathematics Course. Proceedings International Conference on Mathematics/Science Education $\&$ Technology. Charlottesville, Virginia Association for the Advisement of Computing in Education.

[36] Shafim-Mousavi, M. And Kochanowski, P. $1998 \mathrm{a}$. MATHEMATICS IN ACTION: Social and Industrial Problems. 1998 Mathematical Modeling Symposia. Proceedings. University of Wisconsin - La Crosse, 
Wisconsin

[37] Shafil-Mousavi, M. and Kochanowski, P. $1998 \mathrm{~b}$. http://oit.iusb.edu/ mshafii/math-in-action.html

[38] Sungur, E.A., J.E. Anderson, And B.S.

Winchester. 2005. Integration of service learning into statistics education. In Hadlock 2005 101-110.

[39] Watkins, T.L. 1996. Creating a New MBA Core with Team Teaching. Journal of Management Education Vol. 20, Issue 4, p. 411.

[40] Webster, J., And C. Vinsonhaler. 2005. Getting down to work- A "how-to" guide for designing and teaching a service- learning course. In Hadlock 2005
247- 264 .

[41] Wilke, R.R. 2002. Practical considerations for assessing inquiry-based instruction. Journal of College Science Teaching 31 (7): 432-435.

[42] Winston, W.L. 1994. Operations Research Wadsworth Publishing Company, Belmont, California

[43] Wood, B. 2003. Improving wellness on campus. Journal of College Science Teaching 33 (2): 2731.

[44] Young, M. B. And Kram, K. E. 1996. Repairing the Disconnects in Faculty Teaching Teams. Journal of Management Education 20, Issue 4, p. 500. 